\title{
Editorial
}

\section{The Management of Obesity in People with Severe Mental Illness: An Unresolved Conundrum}

\author{
Richard I.G. Holt \\ Human Development and Health, Faculty of Medicine, University of Southampton, Southampton, UK
}

\author{
Keywords \\ Obesity - Weight gain - Antipsychotics - Lifestyle \\ interventions . Pharmacotherapy
}

\section{Introduction}

There can be little doubt in anyone's mind that obesity is a major global public health challenge. The prevalence has steadily risen over recent decades to the point where overweight and obesity now affect more than two billion people or $30 \%$ of the world's population, a rate that has tripled since 1975 [1]. Obesity comes at a huge personal cost through a range of medical illnesses from metabolic conditions such as diabetes, through musculoskeletal disorders to cardiovascular disease and various cancers as well as impaired mental well-being and reduced life chances. In terms of the societal cost, the economic impact of obesity was estimated at USD 2 trillion in 2014, through increased health expenditure, lost productivity and disability [2].

At its core, the cause of obesity appears simple, namely, consuming more calories than are expended but experience dictates that the causes are much more complex

\section{KARGER}

(c) 2019 S. Karger AG, Basel

E-Mail karger@karger.com

www.karger.com/pps and include both individual and societal factors. Dietary patterns have changed with an increased intake of energy-dense foods that are rich in fat and refined sugars, while physical activity has dropped both at work and leisure. Although, some might view these as personal responsibility, the observation that obesity affects the most socially disadvantaged people, at least in high-income countries, would argue that a lack of governmental policy has contributed to the epidemic by failing to create a healthy environment through transport and urban planning and support for healthy food choices.

\section{Obesity in People with Severe Mental IIIness}

People with severe mental illness have been disproportionately affected by the obesity epidemic; in contrast to historical descriptions of an "asthenic" body habitus, recent studies indicate that obesity rates have increased substantially among people with severe mental illness and at a quicker rate than the general population $[3,4]$. Changes in body composition are recognised early in the natural history with people with first-episode psychosis being more likely to have overweight and obesity [5]. Rapid 
weight gain occurs after treatment initiation with antipsychotics, however, and this continues, albeit at a slower rate, in the following years [5-7]. Overall the prevalence of overweight and obesity is 2 - to 3 -fold higher than that in the general population [3].

All antipsychotics can lead to substantial weight gain with $37-86 \%$ of those with first-episode psychosis experiencing more than $7 \%$ of body weight gain during the first year of treatment $[5,8]$. The propensity to weight gain differs between drugs with the greatest weight gain observed with olanzapine and clozapine [9]. Although much of the focus of research in this area has been on second-generation antipsychotics, weight gain may also occur with first-generation antipsychotics with chlorpromazine being associated with the most weight gain [10].

Although there is a marked inter-individual variation in weight change with antipsychotic treatment ranging from weight gain to loss [11], several demographic and clinical features are associated with more weight gain. These include antipsychotic-naïve younger people with first-episode psychosis, florid psychotic features, lower initial body mass index, non-white European ethnicity, a tendency to overeat at times of stress and concomitant cannabis usage [3]. The best predictor of long-term antipsychotic-induced weight gain, however, is rapid weight gain in the first 6 weeks of treatment [6].

The precise mechanisms by which antipsychotics induce weight gain are not fully understood. Although antipsychotics decrease energy expenditure $[12,13]$ and alter the gut microbiome in ways that could lead to weight gain [14], the effects of antipsychotics on appetite and food intake are the predominant mechanism [3]. Appetite regulation is complex and involves multiple neuropeptides, some of which are affected by antipsychotics [15]. The most important receptor interactions are with the 5-hydroxtryptamine $2 \mathrm{C}\left(5-\mathrm{HT}_{2 \mathrm{C}}\right)$ receptor [12], histamine $\mathrm{H}_{1}$ receptors [16] and dopamine receptors [17].

Antipsychotics, however, do not provide the whole explanation as unhealthy food choices, physical inactivity and social deprivation are also important aetiological factors in the development of obesity in this population [18, 19]. Disease-specific factors such as altered neuro-endocrine functioning may also play a role [3].

Obesity is an important contributor to the excess morbidity and mortality experienced by people with severe mental illness and may also worsen self-esteem and lead to further stigmatisation of those taking antipsychotics [20]. Weight gain may be one reason why people discontinue antipsychotic treatment with the risk of relapse and hospi- talisation. There is a clear and pressing need to develop interventions for people with severe mental illness to support weight loss and a reduction in health inequality.

\section{Challenges of Obesity Management}

Everyday experience would suggest that managing overweight and obesity is challenging, and it is important to recognise that obesity is a long-term condition for which we have no cure, only treatments, and even these are not that effective. As Arya Sharma, past-Chair in Obesity Research and Management at the University of Alberta, Edmonton, so insightfully remarked, "Telling someone with obesity to lose weight is about as effective as telling someone with depression to cheer up" [21]. Weight rebound all too frequently occurs after behavioural interventions as the body has powerful homeostatic mechanisms to protect against weight loss [22, 23]. These include diminished signals from the gastro-intestinal tract to indicate nutrient ingestion, impaired signalling from fat stores and increased brain responses to food cues [24]. Even after bariatric surgery, the most effective treatment for obesity, some individuals do not lose weight [25].

Despite these challenges, some people can lose weight through lifestyle interventions whether these are undertaken individually or provided commercially or within health settings. One of the most impressive recent trials was the Diabetes Remission Clinical trial (DiRECT), which employed a low-calorie total diet replacement followed by stepped food reintroduction and support in people with type 2 diabetes. After 1 year, nearly a quarter of participants had lost more than $15 \mathrm{~kg}$ in weight and by 2 years, an average weight loss of $10 \mathrm{~kg}$ was maintained $[26,27]$. The authors attribute their success to four key criteria: (1) an initial assessment using defined criteria for suitability of the individual to the programme; (2) an integrated programme with a focus on long-term behaviour change and strategies for relapse management, which should be introduced at the start of the programme; (3) protocols for management of anti-diabetes and anti-hypertensive medications and; (4) prospective data collection and audit for continuous programme improvement [28]. Other important mediators of success reported in the wider literature include higher levels of autonomous motivation, greater self-efficacy and self-regulation as well as positive body image and social support [29, 30], issues that surely affect people with severe mental illness to a greater extent than the general population. 


\section{Lifestyle Interventions in People with Severe Mental Illness}

There has been a widespread feeling of nihilism towards lifestyle interventions in people with severe mental illness; the argument goes along the lines that if the general population cannot lose weight with lifestyle change, what hope is there of success in people with severe mental illness. Despite this pessimism, a considerable amount of work has been undertaken to develop appropriate lifestyle interventions in this population and initially suggested that, contrary to expectation, lifestyle interventions could be effective. In 2012, Caemmerer et al. [31] published a meta-analysis of 17 studies including 810 people receiving antipsychotics, which showed that lifestyle interventions led to a mean weight reduction of just over $3 \mathrm{~kg}$, alongside improvements in other cardiovascular risk factors. The conclusions were, however, limited by the short duration of most trials (12-16 weeks) and the low number of participants (median 53, range 15-110). The National Institute of Health and Clinical Excellence (NICE) produced an expanded literature review of 24 studies in 2014 and came to broadly the same conclusions [32]. NICE, however, was more critical of the evidence; again, it noted the short duration of follow-up and small numbers but also commented on the high risk of bias and substantial heterogeneity of effect size between studies. Further concern about the effectiveness of lifestyle interventions was raised in a meta-analysis by Naslund et al. [33]. Although the authors reported an overall significant weight reduction in the 6 studies that lasted longer than a year, it is noteworthy that only 2 studies achieved a statistically significant weight loss and both of these included a diverse population of people receiving antipsychotics.

Despite the inconsistencies in the literature, national and international guideline groups have been quick to recommend the provision of lifestyle interventions for people with severe mental illness. For example, NICE recommends that "people with psychosis or schizophrenia, especially those taking antipsychotics, should be offered a combined healthy eating and physical activity programme by their mental healthcare provider," while the World Federation of Societies of Biological Psychiatry recommends psychosocial interventions to treat weight gain $[32,34]$. Healthcare providers are, however, left in the quandary of being required to provide services for people with severe mental illness without knowing exactly what these should involve.
Given the uncertainty in the literature and the resources currently being dedicated towards lifestyle intervention in people with severe mental illness, the meta-analysis by Speyer et al. [35] published in this issue is both timely and instructive. The meta-analysis, which is the largest to date, included 41 randomised controlled trials and 4,267 participants. The interventions reduced mean BMI by $0.63 \mathrm{~kg} / \mathrm{m}^{2}$, equivalent to a weight loss of $2.2 \mathrm{~kg}$ in association with a reduction of waist circumference. Intervention participants were $50 \%$ more likely to lose weight than control participants. This effect size is smaller than earlier reports and, as a 5\% weight loss is generally recommended to improve health, is likely not to be clinically relevant.

When reported, the lifestyle intervention had no effect on quality of life, other cardiovascular risk factors, mortality or hospitalisation, although these negative findings likely reflect inadequate power as most trials were of too short duration to assess hard long-term outcomes.

There was considerable heterogeneity between trials, and it is noteworthy that Asian trials were more effective than trials undertaken in the USA, which in turn were better than European trials. It seems likely that these differences result from a number of confounding factors, such as provision of healthcare delivery and consultation style, rather than geographical location. Individual sessions were more effective than group sessions. Together, these two factors explained almost two-thirds of the heterogeneity. Interestingly, neither duration nor intensity of the intervention predicted its outcome. More recent and rigorous studies were less likely to demonstrate a beneficial effect, which may explain the smaller effect size than in earlier meta-analyses.

\section{Complex Interventions}

So where does this leave us regarding the management of overweight and obesity in people with severe mental illness? Before abandoning lifestyle interventions in favour of other interventions, it is worth considering again the heterogeneity both within and between trials. In the STEPWISE trial, the range of weight change was from 30 $\mathrm{kg}$ weight gain to $25 \mathrm{~kg}$ weight loss, suggesting that some individuals respond to lifestyle interventions while others do not [19]. We need to know much more about the predictors of success so that clinicians can assess an individual's suitability for any programme offered [28].

Obesity interventions are plagued with high drop-out rates, and consistent with general population lifestyle in- 
tervention trials, Speyer's meta-analyses highlights that $\sim 15 \%$ of participants discontinued their trial [36]. This is unsurprising as people are quick to recognize a lack of treatment effect and become discouraged; further work is needed to understand how to keep people engaged in these programmes as long-term attendance can predict greater weight loss.

Another challenge facing clinicians and researchers is the poor description of interventions. By definition, these are complex and it is not easy to assess what are the "active ingredients" of any one intervention. Given the lack of detail, it would be challenging for any clinician to faithfully replicate an intervention. Much better reporting is needed in future and perhaps should be made mandatory by journal editors, particularly now that it is so easy to publish supplementary material on the journal website.

\section{Alternatives to Lifestyle Management}

\section{Switching Antipsychotics or Treatments}

Given the different propensity between antipsychotics to induce weight gain, switching to an antipsychotic with less weight gain appears a sensible approach. Unfortunately, there is little evidence to support this; nevertheless, a few studies have reported that switching from olanzapine to aripiprazole or quetiapine may be beneficial, although any switch must balance the risk of a deterioration in mental health [37]. Adding aripiprazole to clozapine or olanzapine has also been shown to result in a modest weight reduction of $\sim 2 \mathrm{~kg}$ [38]. As there is little evidence of an antipsychotic dose response with regard to weight gain, lowering the antipsychotic dose rarely achieves weight loss.

Alternatives to antipsychotics can be considered for bipolar illness or depression but weight gain may also occur with these treatments. Again, there appears to be a hierarchy of risk with antidepressants with paroxetine, amitriptyline and mirtazapine being associated with the most weight gain; by contrast, bupropion is associated with weight loss, while fluoxetine and sertraline appear weight neutral [39].

\section{Pharmacotherapy}

Although metformin has very little effect on body weight in the general population, this drug is the most extensively studied in the context of severe mental illness and is associated with a mean reduction in body weight of $3.3 \mathrm{~kg}$ over 3-6 months [40]. Nevertheless, the lack of long-term stud- ies means it is unclear whether this weight loss would be maintained over the years of antipsychotic treatment. Many other drugs have been studied, of which orlistat, reboxetine and topiramate are associated with a small reduction in weight; however, none has the evidence base to recommend their routine use, not least because of the adverse effects of these drugs [41]. The most promising new drug class is the glucagon-like peptide-1 (GLP-1) receptor agonists. These drugs are used to treat diabetes and cause weight loss as well as improved glucose control. Liraglutide is also licensed as an obesity medication at a higher dose [42]. Three trials of GLP-1 receptor agonists have been completed in people taking antipsychotics, two of which demonstrated a weight reduction of over $5 \mathrm{~kg}$ [42-44]. A further trial of the obesity dose of liraglutide in people with schizophrenia is currently ongoing (Universal Trial Number U1111-1203-0068; EudraCT: 2017-004064-35).

\section{Surgery}

There is little experience of bariatric surgery in people with severe mental illness, but psychosis should not be seen as a contraindication where an individual has severe obesity and where otherwise surgery would be recommended [45].

\section{Mitigating the Effects of Weight Gain}

In a previous editorial in this journal, Fava and Rafanelli [46] applied the concept of "cascade iatrogenesis" to discuss how a series of multiple medical complications can be set in motion by a seemingly innocuous first event. In their editorial, they discussed the long-term effects of initiating antidepressants, but this concept can be applied equally well to antipsychotics, given the long-term sequelae of weight gain.

It is important that measures are taken from the onset of treatment to prevent weight gain. Although Speyer's meta-analysis included studies of lifestyle interventions to prevent weight gain, few have been conducted in very early psychosis. One study, however, from Australia suggests that a comprehensive approach to body and mind in early psychosis may attenuate weight gain [47].

Guidelines consistently recommend that weight is monitored regularly during the early phases of treatment to identify those individuals who gain weight rapidly after treatment initiation to whom interventions can be targeted [48]. The guidelines also advocate regular laboratory measurement to screen for diabetes and cardiovascular risk. 
There is an urgent clinical need to develop robust interventions to address overweight and obesity in people with severe mental illness. It is clear that we are a long way from the ideal solution and much more work is needed to understand how best to tackle this problem. Given the complexity of obesity, it is likely that one approach will not suit all individuals. Within the general population, obesity guidelines recommend a tiered approach beginning with lifestyle and moving through pharmacotherapy to bariatric surgery for those with the most severe and intractable disease [49-51]. Perhaps the time has come where future research into managing obesity in people with severe mental illness should also examine care pathways rather than just the individual components.

\section{Disclosure Statement}

The author has received fees for lecturing, consultancy work, and attendance at conferences from the following: AstraZeneca, Boehringer Ingelheim, Eli Lilly, Janssen, Lundbeck, Mylan, Novo Nordisk, Novartis, Otsuka, Sanofi, Sunovion, and Takeda. The author is the chief investigator of the trial of $3 \mathrm{mg}$ liraglutide in people with schizophrenia (UTN U1111-1203-0068; EudraCT: $2017-$ 004064-35).

\section{Funding Sources}

No funding was received for the preparation of this editorial.

\section{References}

1 World Health Organisation. Overweight and obesity. 2018 [cited 2019 Sep 16]. Available from: https://wwwwho.int/news-room/factsheets/detail/obesity-and-overweight.

2 Dobbs R, Sawers C, Thompson F, Manyika J, Woetzel JR, Child P, et al. Overcoming Obesity: An Initial Economic Analysis. Jakarta, Indonesia: McKinsey Global Institute; 2014.

3 Holt RI, Peveler RC. Obesity, serious mental illness and antipsychotic drugs. Diabetes Obes Metab. 2009 Jul;11(7):665-79.

4 Holt RI. Obesity - an epidemic of the twentyfirst century: an update for psychiatrists. J Psychopharmacol. 2005 Nov;19(6 Suppl):615.

5 Kahn RS, Fleischhacker WW, Boter H, Davidson $M$, Vergouwe $\mathrm{Y}$, Keet IP, et al.; EUFEST study group. Effectiveness of antipsychotic drugs in first-episode schizophrenia and schizophreniform disorder: an open randomised clinical trial. Lancet. 2008 Mar; 371(9618):1085-97.

6 Kinon BJ, Kaiser CJ, Ahmed S, Rotelli MD, Kollack-Walker S. Association between early and rapid weight gain and change in weight over one year of olanzapine therapy in patients with schizophrenia and related disorders. J Clin Psychopharmacol. 2005 Jun; 25(3):255-8.

7 Tek C, Kucukgoncu S, Guloksuz S, Woods SW, Srihari VH, Annamalai A. Antipsychotic-induced weight gain in first-episode psychosis patients: a meta-analysis of differential effects of antipsychotic medications. Early Interv Psychiatry. 2016 Jun;10(3):193-202.

8 Citrome L, Holt RI, Walker DJ, Hoffmann VP. Weight gain and changes in metabolic variables following olanzapine treatment in schizophrenia and bipolar disorder. Clin Drug Investig. 2011;31(7):455-82.
9 Allison DB, Mentore JL, Heo M, Chandler LP, Cappelleri JC, Infante MC, et al. Antipsychotic-induced weight gain: a comprehensive research synthesis. Am J Psychiatry. 1999 Nov; 156(11):1686-96.

10 Holt RI. Association Between Antipsychotic Medication Use and Diabetes. Curr Diab Rep. 2019 Sep;19(10):96.

11 Lieberman JA, Stroup TS, McEvoy JP, Swartz MS, Rosenheck RA, Perkins DO, et al.; Clinical Antipsychotic Trials of Intervention Effectiveness (CATIE) Investigators. Effectiveness of antipsychotic drugs in patients with chronic schizophrenia. N Engl J Med. 2005 Sep; 353(12):1209-23.

12 Lord CC, Wyler SC, Wan R, Castorena CM, Ahmed N, Mathew D, et al. The atypical antipsychotic olanzapine causes weight gain by targeting serotonin receptor 2C. J Clin Invest. 2017 Sep;127(9):3402-6.

13 Coccurello R, Brina D, Caprioli A, Conti R, Ghirardi O, Schepis F, et al. 30 days of continuous olanzapine infusion determines energy imbalance, glucose intolerance, insulin resistance, and dyslipidemia in mice. J Clin Psychopharmacol. 2009 Dec;29(6):576-83.

14 Davey KJ, Cotter PD, O'Sullivan O, Crispie F, Dinan TG, Cryan JF, et al. Antipsychotics and the gut microbiome: olanzapine-induced metabolic dysfunction is attenuated by antibiotic administration in the rat. Transl Psychiatry. 2013 Oct;3(10):e309.

15 Chen J, Huang XF, Shao R, Chen C, Deng C. Molecular mechanisms of antipsychotic drug-induced diabetes. Front Neurosci. 2017 Nov;11:643.
16 He M, Zhang Q, Deng C, Wang H, Lian J, Huang XF. Hypothalamic histamine H1 receptor-AMPK signaling time-dependently mediates olanzapine-induced hyperphagia and weight gain in female rats. Psychoneuroendocrinology. 2014 Apr;42:153-64.

17 Deng C. Effects of antipsychotic medications on appetite, weight, and insulin resistance. Endocrinol Metab Clin North Am. 2013 Sep; 42(3):545-63.

18 McCreadie RG; Scottish Schizophrenia Lifestyle Group. Diet, smoking and cardiovascular risk in people with schizophrenia: descriptive study. Br J Psychiatry. 2003 Dec;183(6):534-9.

19 Holt RI, Gossage-Worrall R, Hind D, Bradburn MJ, McCrone P, Morris T, et al. Structured lifestyle education for people with schizophrenia, schizoaffective disorder and first-episode psychosis (STEPWISE): randomised controlled trial. Br J Psychiatry. 2019 Feb;214(2):63-73.

20 Laursen TM, Nordentoft M, Mortensen PB. Excess early mortality in schizophrenia. Annu Rev Clin Psychol. 2014;10(1):425-48.

21 Sharma A. Counting calories for weight loss: more of the same [cited 2019 Sep 16]. Available from: http://wwwdrsharmaca/countingcalories-for-weight-loss-more-of-the-same.

22 Wadden TA. Treatment of obesity by moderate and severe caloric restriction. Results of clinical research trials. Ann Intern Med. 1993 Oct;119(7 Pt 2):688-93.

23 Mann T, Tomiyama AJ, Westling E, Lew AM, Samuels B, Chatman J. Medicare's search for effective obesity treatments: diets are not the answer. Am Psychol. 2007 Apr;62(3):220-33.

24 Sumithran P, Proietto J. The defence of body weight: a physiological basis for weight regain after weight loss. Clin Sci (Lond). $2013 \mathrm{Feb}$; 124(4):231-41. 
25 Adams TD, Davidson LE, Litwin SE, Kim J, Kolotkin RL, Nanjee MN, et al. Weight and metabolic outcomes 12 years after gastric bypass. N Engl J Med. 2017 Sep;377(12):114355.

26 Lean ME, Leslie WS, Barnes AC, Brosnahan N, Thom G, McCombie L, et al. Primary careled weight management for remission of type 2 diabetes (DiRECT): an open-label, clusterrandomised trial. Lancet. 2018 Feb; 391(10120):541-51.

27 Lean ME, Leslie WS, Barnes AC, Brosnahan N, Thom G, McCombie L, et al. Durability of a primary care-led weight-management intervention for remission of type 2 diabetes: 2 -year results of the DiRECT open-label, cluster-randomised trial. Lancet Diabetes Endocrinol. 2019 May;7(5):344-55.

28 Hopkins MD, Taylor R, Lean ME. The DiRECT principles: giving Type 2 diabetes remission programmes the best chance of success. Diabet Med.2019 Sep;4(Sep):dme.14126. ; Epub ahead of print.

29 Teixeira PJ, Carraça EV, Marques MM, Rutter H, Oppert JM, De Bourdeaudhuij I, et al. Successful behavior change in obesity interventions in adults: a systematic review of self-regulation mediators. BMC Med. 2015 Apr; 13(1):84.

30 Jerome GJ, Myers VH, Young DR, MatthewsEwald MR, Coughlin JW, Wingo BC, et al. Psychosocial predictors of weight loss by race and sex. Clin Obes. 2015 Dec;5(6):342-8.

31 Caemmerer J, Correll CU, Maayan L. Acute and maintenance effects of non-pharmacologic interventions for antipsychotic associated weight gain and metabolic abnormalities: a meta-analytic comparison of randomized controlled trials. Schizophr Res. 2012 Sep;140(1-3):159-68.

32 NICE. National Collaborating Centre for Mental Health, Psychosis and schizophrenia in adults: treatment and management CG178. London: The British Psychological Society and The Royal College of Psychiatrists; 2014.

33 Naslund JA, Whiteman KL, McHugo GJ, Aschbrenner KA, Marsch LA, Bartels SJ. Lifestyle interventions for weight loss among overweight and obese adults with serious mental illness: a systematic review and metaanalysis. Gen Hosp Psychiatry. 2017 Jul;47: 83-102.

34 Hasan A, Falkai P, Wobrock T, Lieberman J, Glenthoj B, Gattaz WF, et al.; WFSBP Task force on Treatment Guidelines for Schizophrenia. World Federation of Societies of Biological Psychiatry (WFSBP) guidelines for biological treatment of schizophrenia, part 2: update 2012 on the long-term treatment of schizophrenia and management of antipsychotic-induced side effects. World J Biol Psychiatry. 2013 Feb;14(1):2-44.

35 Speyer H, Jakobsen AS, Westergaard C, Nørgaard HC, Pisinger C, Krogh J, et al. Lifestyle interventions for weight management in people with serious mental illness: a systematic review with meta-analysis, trial sequential analysis and meta-regression analysis, exploring the mediators and moderators of treatment effects. Psychother Psychosom. 2019 Sep;1-13.

36 Miller BM, Brennan L. Measuring and reporting attrition from obesity treatment programs: A call to action! Obes Res Clin Pract. 2015 May-Jun;9(3):187-202.

37 Mukundan A, Faulkner G, Cohn T, Remington G. Antipsychotic switching for people with schizophrenia who have neuroleptic-induced weight or metabolic problems. Cochrane Database Syst Rev. 2010 Dec;(12):CD006629.

38 Mizuno Y, Suzuki T, Nakagawa A, Yoshida K, Mimura M, Fleischhacker WW, et al. Pharmacological strategies to counteract antipsychotic-induced weight gain and metabolic adverse effects in schizophrenia: a systematic review and meta-analysis. Schizophr Bull. 2014 Nov; 40(6):1385-403.

39 Serretti A, Mandelli L. Antidepressants and body weight: a comprehensive review and meta-analysis. J Clin Psychiatry. 2010 Oct; 71(10):1259-72.

40 de Silva VA, Suraweera C, Ratnatunga SS Dayabandara M, Wanniarachchi N, Hanwella R. Metformin in prevention and treatment of antipsychotic induced weight gain: a systematic review and meta-analysis. BMC Psychiatry. 2016 Oct; $16(1): 341$.

41 Cooper SJ, Reynolds GP, Barnes T, England E, Haddad PM, Heald A, et al.; With expert co-authors (in alphabetical order). BAP guidelines on the management of weight gain, metabolic disturbances and cardiovascular risk associated with psychosis and antipsychotic drug treatment. J Psychopharmacol. 2016 Aug;30(8):717-48.

42 Ishøy PL, Knop FK, Broberg BV, Bak N, Andersen UB, Jørgensen NR, et al. Effect of GLP1 receptor agonist treatment on body weight in obese antipsychotic-treated patients with schizophrenia: a randomized, placebo-controlled trial. Diabetes Obes Metab. 2017 Feb; 19(2):162-71.

43 Siskind DJ, Russell AW, Gamble C, Winckel K, Mayfield K, Hollingworth S, et al. Treat- ment of clozapine-associated obesity and diabetes with exenatide in adults with schizophrenia: A randomized controlled trial (CODEX). Diabetes Obes Metab. 2018 Apr;20(4): 1050-5.

44 Larsen JR, Vedtofte L, Jakobsen MS, Jespersen HR, Jakobsen MI, Svensson CK, et al. Effect of liraglutide treatment on prediabetes and overweight or obesity in clozapine- or olanzapine-treated patients with schizophrenia spectrum disorder: a randomized clinical trial. JAMA Psychiatry. 2017 Jul;74(7):719-28.

45 Kouidrat Y, Amad A, Stubbs B, Moore S, Gaughran F. Surgical management of obesity among people with schizophrenia and bipolar disorder: a systematic review of outcomes and recommendations for future research. Obes Surg. 2017 Jul;27(7):1889-95.

46 Fava GA, Rafanelli C. Iatrogenic factors in psychopathology. Psychother Psychosom. 2019;88(3):129-40.

47 Teasdale SB, Curtis J, Ward PB, Watkins A, Lederman O, Rosenbaum S, et al. The effectiveness of the Keeping the Body in Mind Xtend pilot lifestyle program on dietary intake in first-episode psychosis: two-year outcomes. Obes Res Clin Pract. 2019 Mar - Apr; 13(2):214-6.

48 Holt RI. The prevention of diabetes and cardiovascular disease in people with schizophrenia. Acta Psychiatr Scand. 2015 Aug; 132(2):86-96.

49 Jensen MD, Ryan DH, Apovian CM, Ard JD, Comuzzie AG, Donato KA, et al.; American College of Cardiology/American Heart Association Task Force on Practice Guidelines: Obesity Society. 2013 AHA/ACC/TOS guideline for the management of overweight and obesity in adults: a report of the American College of Cardiology/American Heart Association Task Force on Practice Guidelines and The Obesity Society. Circulation. 2014 Jun; 129(25 Suppl 2):S102-38.

50 Yumuk V, Tsigos C, Fried M, Schindler K, Busetto L, Micic D, et al.; Obesity Management Task Force of the European Association for the Study of Obesity. European guidelines for obesity management in adults. Obes Facts. 2015;8(6):402-24.

51 Garvey WT, Mechanick JI, Brett EM, Garber AJ, Hurley DL, Jastreboff AM, et al.; Reviewers of the AACE/ACE Obesity Clinical Practice Guidelines. American Association of Clinical Endocrinologists and American College of Endocrinology comprehensive clinical practice guidelines for medical care of patients with obesity. Endocr Pract. 2016 Jul;22 Suppl 3:1-203. 